\title{
PHẪU THUẬT DỊ DẠNG LỒI NGỰC BẨM SINH
}

Vũ Hũu Vĩnh * Huỳnh Quang Khánh *

\section{TÓM TẮT}

Hồi cứu mô tả những trường hợp phẫu thuật lồi ngực trong vòng 5 năm (2009-2013) tại bệnh viện Chợ Rẫy. Bệnh nhân được đặt 2 thanh nâng ngực ở trong ngực với mục đích nâng phần lõm và làm dãn rộng 2 bên thành ngực. Phần ngực lồi ra được cắt gọt tạo mặt phẳng cho thành ngực. Thời gian rút thanh ngực là 3 năm. Kết quả: Có 11 bệnh nhân được phẫu thuật. Về mặt hình thể, kết quả tốt ở 9 trường hợp, kết quả khá 1 trường hợp và 1 trường hợp kết quả kém, không thay đổi so với trước mổ. Tất cả các trường hợp sau rút thanh ngực không có biến chứng gì, lồng ngực tròn đều, các bệnh nhân hài lòng với hình dáng ngực và cho biết sức khoẻ được cải thiện rõ.

Tù khóa: Lồi ngực, lõm ngực, dị dạng thành ngực, phẫu thuật chỉnh sửa, thanh ngực

\section{REPAIR SURGERY FOR PECTUS CARINATUM}

\section{SUMMARY}

Retrospective review pectus carinatum cases repaired by surgery during 5 years $(2009-2013)$ at our Thoracic Dept. Choray Hospital. Two pectus bars were inserted into the chest cavity to propel the sunken parts and widen both lateral parts of the chest wall. The protrude parts of the chest wall ablated, forming smooth curvature for the chest wall. Pectus bars will be removed after 3 years. Results: 11 cases of pectus carinatum were repaired by surgery. The shape of the chest wall were much improved in 9 cases, good in one and not better in one. Bars removed cases showed no complication, have good shape for the chest wall and express satisfaction.

Keywords: pectus carinatum, pectus excavatum, pectus deformity, repair surgery, pectus bar

*Dept. of Thoracic Surgery. Choray Hospital

\section{I. ĐẠTT VẤN ĐỀ}

Lồi ngực (pectus carinatum) là một dạng dị dạng bẩm sinh thành ngực phía trước. Nó ngược với lõm ngực, lồng ngực không lõm vào trong mà lổi ra ngoài, hoặc vừa lồi vừa lõm. Phần lồi ra bao gồm có 2 loại, xưng ức bẻ góc chữ $\mathrm{V}$, lồi ra ngoài hoặc phần sụn cạnh ức của các xương sườn lồi lên, hoặc phối hợp cả 2. Nó còn được gọi là ngực gà, hay ngực chim bồ câu (pigeon breast ). Lồi ngực thường không ảnh hưởng đến tim và phổi tuy nhiên do hình dáng lồi phía trước thường kép hẹo 2 bên khung sườn làm chức năng hô hấp hô hấp ít nhiều bị ảnh hưởng. Người có dị dạng này thường có sức khoẻ nói chung kém hơn và khả năng chịu đựng, chống đỡ với bệnh tật cũng kém hơn, đặc biệt là đối với các bệnh đường hô hấp. Hơn nữa, cũng như lõm ngực, người bị lồi ngực thường có tâm lý mặc cảm với bộ ngực dị dạng, thiếu tự tin và ngại lộ ngực chỗ đông người.

* Khoa ngoại Lồng ngưc, Bệnh viện Chợ Rẫy, TP HCM.

Nguoòi chịu trách nhiẹm khoa học: TS Vũ Hũu Vĩnh

- Ngày nhân bài: 20/03/2015

- Ngày Cho Phép Đăng: 27/03/2015

Phản Biện Khoa họ: PGS.TS. Đặng Ngoc Hùng PGS.TS. Lê Ngọc Thành 


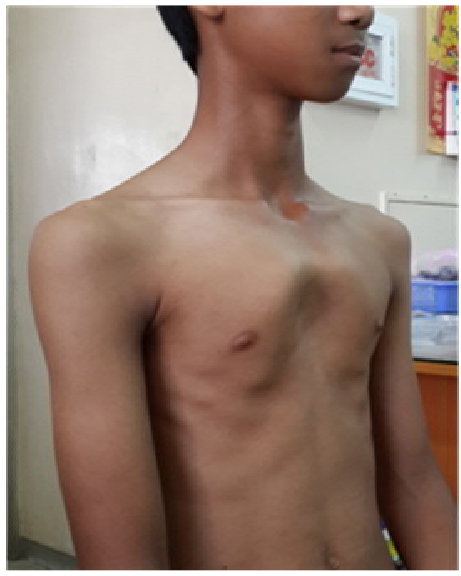

H.1 Lồi ngực có gập góc xương ức

Lồi ngực bẩm sinhcó tỷ lệ vào khoảng 1: 1500 trẻ, ít hơn nhiềuso với tỷ lệ 1: 400 của lõm ngực. Lồi ngực xảy ra ở bé trai nhiều hơn bé gái và thường chỉ thấy rõ từ tuổi 12 .

Điều trị lồi ngực bẩm sinh có thể bằng cách đặt khung chỉnh sửa (bracing) hoặc phẫu thuật. Phẫu thuật được cho là cách điều trị cơ bản và có thể sửa cho khung ngực tròn đều, khắc phục được

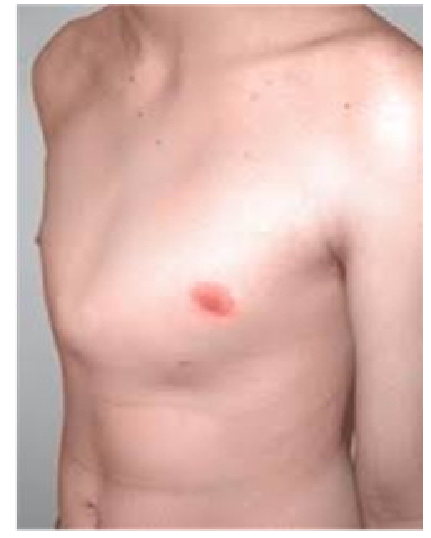

H.2 Lồi ngực không có gập góc xương ức, lồi hõm ức

các vùng lõm phối hợp, hoặc hẹp bề ngang của lồng ngực do phần lồi của xương ức gián tiếp tạo ra. Nhiều trường hợp không thể phẫu thuật chỉnh sửa được ví dụ như lồi ngực $1 / 3$ trên có liên quan đến khớp ức đòn, lồi ngực lệch tâm do lồi xương sườn 2, lồi ngực mà xương ức nhô ra theo chiều dọc, làm bẻ gập góc sườn ức, liên quan đến tất cả các xương sườn gắn vào xương ức.

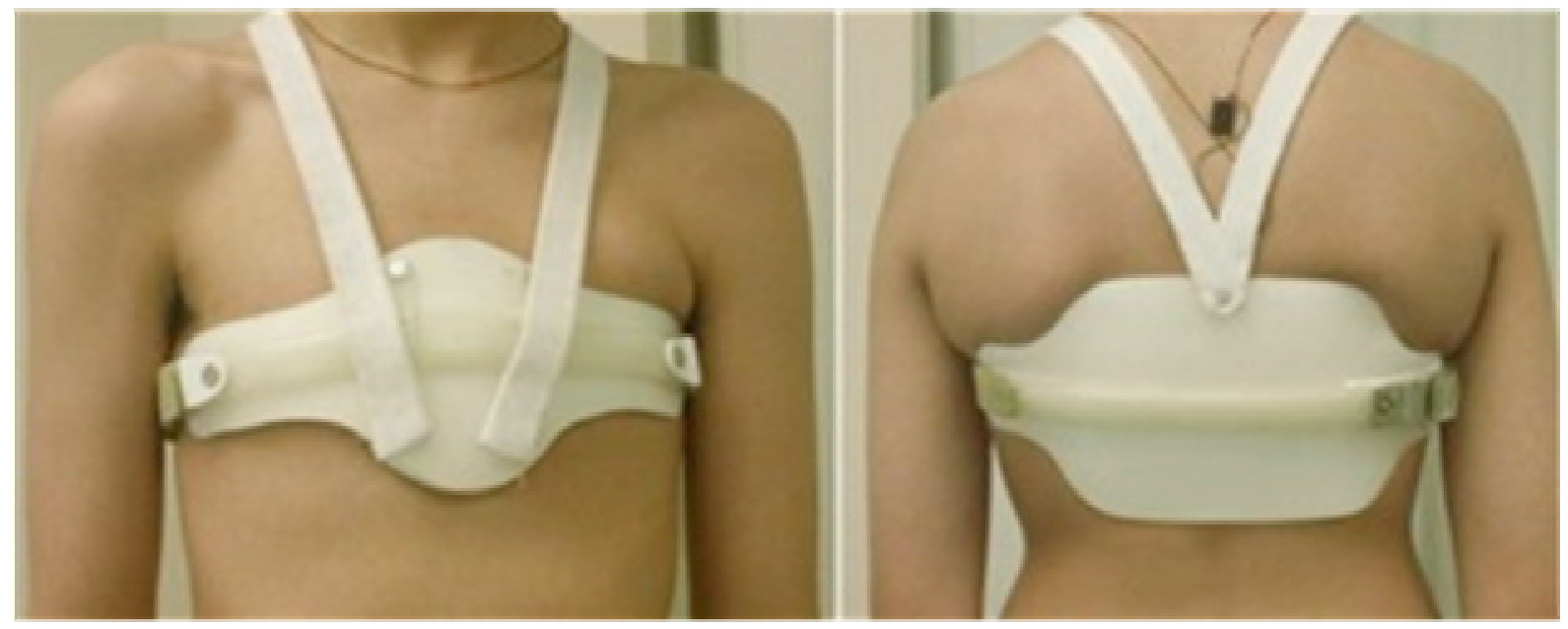

H. 3, H. 4 Đặt khung chỉnh sủa

\section{PHƯƠNG PHÁP NGHIÊN CỨU}

Hồi cứu mô tả các trường hợp lồi ngực đã được phẫu thuật sửa chữa bằng phương pháp đặt thanh ngực phía trong và cắt bỏ phần xương lồi phía ngoài được chúng tôi tiến hành tại bệnh viện Chợ Rẫy trong 5 năm (2009 - 2013).
Bệnh nhân được mổ đặt thanh ngực giống như lõm ngực, thanh uốn hình cong tạo vòm đều, lực chống được nhấn mạnh vào vùng lõm có ưu tiên làm phình lồng ngực ra hai bên hơn là phía trước. Phần ngực lồi được tính toán kỹ lưỡng đề cắt bỏ mà không ảnh hưởng đến cấu trúc chịu lực chung của lồng ngực. 


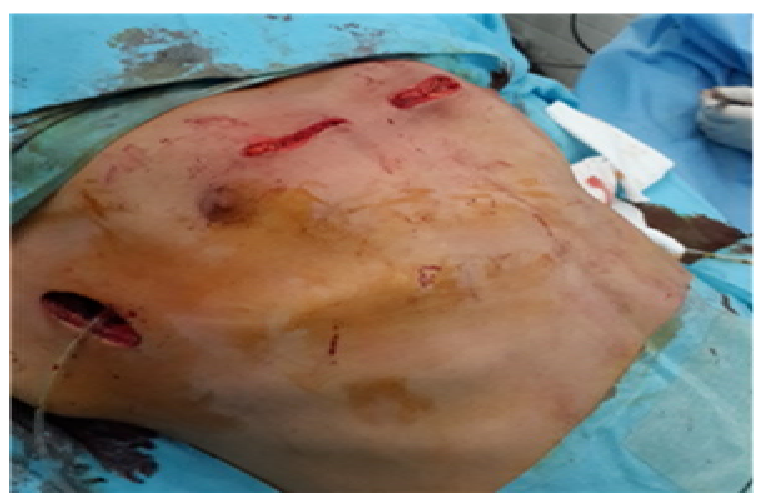

H.5 Sau khi đặt 2 thanh ngục để đẩy lồng ngục tù phía trong, phần lồi của xương úcc và 2 bên sươn được cắt bỏ để bo tròn lồng ngục ở phía ngoài.

\section{KẾT QUẢ}

Chúng tôi đã phẫu thuật cho 1200 cháu có dị dạng lồng ngực ở cả tại bệnh viện chúng tôi và ở một vài bệnh viện khác thì chỉ gặp 18 cháu lồi ngực. Trong đó chỉ phẫu thuật được cho 11 cháu, các cháu còn lại hoặc không có chỉ định mổ hoặc do lúc đầu chúng tôi còn ngần ngại trong việc phẫu thuật cho loại bệnh này. 11 bệnh nhân bị lồi ngực đã được phẫu thuật chỉnh sửa tại bệnh viện Chợ rẫy. Về mặt chức năng, thực chất lồi ngực rất ít ảnh hưởng đến chức năng tim phổi nên đánh giá kết quả phẫu thuật chủ yếu là về mặt hình thể.

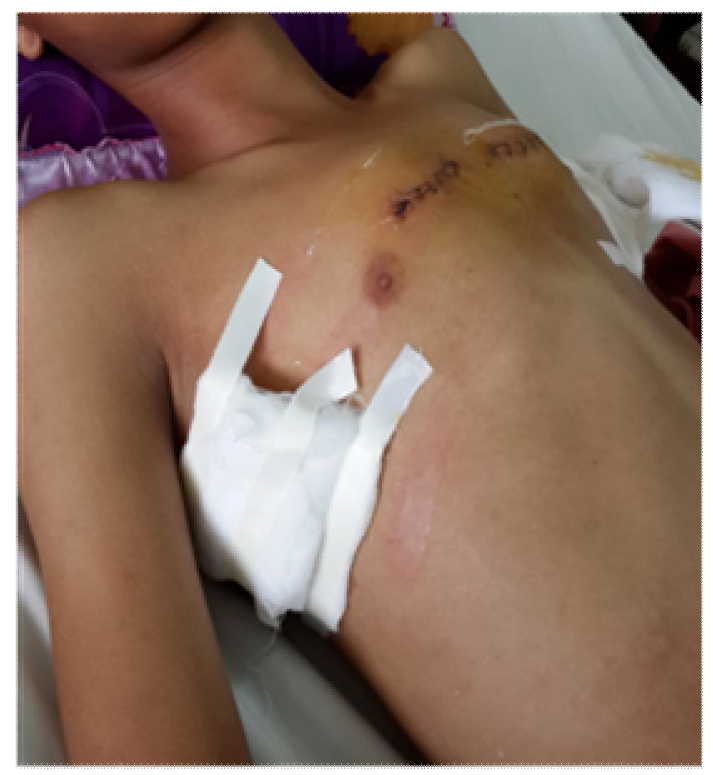

H.6 Sẹo mổ trước lúc cắt chỉ
Trong số 11 cháu được phẫu thuật thì chỉ có 2 bé gái, 9 bé trai. Tuổi trung bình là 12 tuổi, nhỏ nhất 9 tuổi, lớn nhất 14 tuổi.

Không có các biến chứng trong và sau mổ như: như tràn khí, di lệch thanh, chảy máu hay nhiễm trùng sau mổ.

Có 11 bệnh nhân đã được phẫu thuật. Tại thời điểm báo cáo 9 trường hợp đã được rút thanh an toàn còn 2 trường hợp đã được trên 2 năm, chờ đến ngày rút.

Có 2 trường hợp hình lồi còn thấy sau phẫu thuật, 1 trường hợp thấy rõ và một trường hợp còn lồi ít.

Chúng tôi đánh giá kết quả phẫu thuật dựa trên 2 yếu tố: phần lồi mất đi và phần lõm được nâng lên, giống như nắn lại một khung ngực méo mó thành một khung ngực hình ovan tròn đều.

Xét theo tiêu chí này, 9 trường hợp được đánh giá là có kết quả tốt, một trường hợp phần lõm được nâng lên nhưng phần lồi vẫn còn rõ sau mổ mặc dù đã được cắt gọt phần ngoài, một trường hợp kết quả kém, phần lồi và phần lõm vẫn còn do thanh ngực nâng phần lõm di lệch vào phía phần lồi. Đây cũng là trường hợp chúng tôi không cắt gọt phần lồi bên ngoài

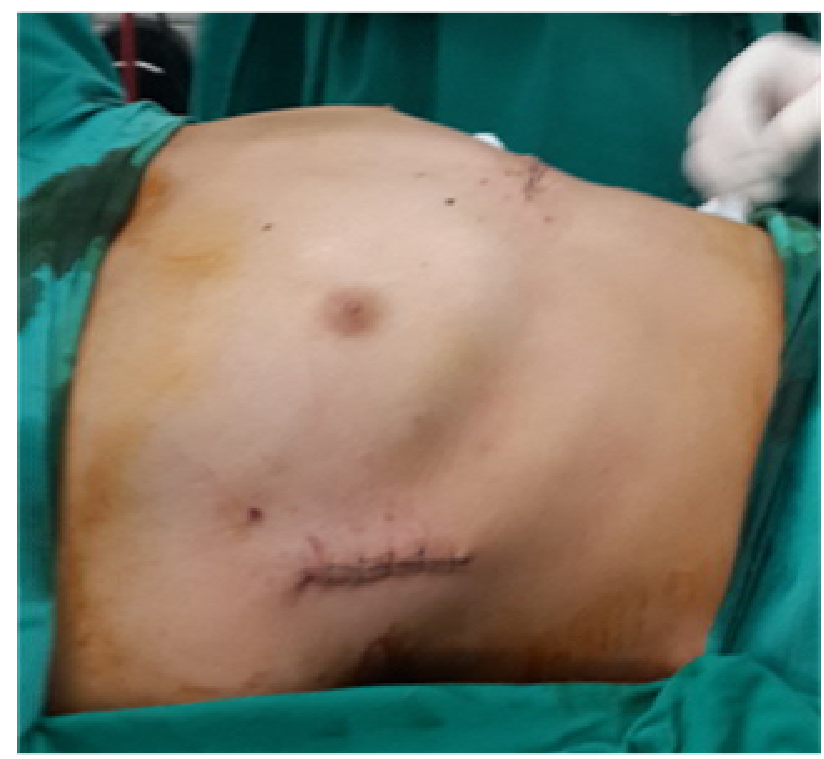

H.7 Kết quả phâu thuật ngay sau mổ loại lồi ngục mũi úc 


\section{BÀN LUẬN}

Lồi ngực ít gặp hơn lõm ngực rất nhiều nhưng lại rất khó để phẫu thuật chỉnh sửa. Các dạng lồi ngực rất đa dạng nhưng tựu chung qui về 2 nhóm chính là lồi ngang và lồi dọc. Lồi ngang là đường lồi ngực nằm ngang, 2 bên là 2 sụn sườn và chính giữa là xương ức (H.1) trong khi lồi dọc thì đường lồi chỉ là cả thân xương ức, còn các xương sườn 2 bên thì xẹp lại, tạo gập góc rõ tại khác khớp ức sườn.

Loại ngang có thể là $1 / 3$ trên, $1 / 3$ giữa hoặc $1 / 3$ dưới (thể mũi ức) (H.2), loại này thường kèm với lõm ngực làm nổi rõ gờ lồi. Loại này cũng có thể đồng tâm hoặc lệch tâm. Loại lõm dọc chủ yếu là đồng tâm với cả xương ức là gờ lồi, nhưng nó cũng có thể lệch tâm nếu gờ lồi rơi vào các sụn sườn của khớp ức sườn 1 bên mà không phải là dọc thân xương ức.

Lồi ngực thường ít ảnh hưởng đến các cơ quan trong lồng ngực như tim và phổi như lõm ngực. Phẫu thuật chình sửa chủ yếu là để nắn lại lồng ngực cho tròn đều, giải quyết vấn đề thẩm mỹ.

Về nguyên tắc phần nào lồi thì được ép xuống hoặc gọt bỏ còn phần lõm thì đẩy từ trong hoặc treo kéo ở ngoài. Phải phối hợp cả 2 loại chỉnh sửa ngày thì mới có thể "nắn" bộ ngực tròn trịa trở lại. Có thể dùng khung nắn chỉnh để kéo phần lõm ra và đẩu phần lồi vào. Phương pháp này rất phức tạp và bệnh nhân phải mang một khung quanh lồng ngực ảnh hưởng rất lớn đến cuộc sống trong thời gian mang khung. Phẫu thuật chỉnh sửa đẩy phần lõm từ phía trong ra bằng đặt 2 thanh ngực (pectus bars) và cắt gọt những phần lồi lên là một lựa chọn tốt (H.5, H.6, H.7). Sau mổ bệnh nhân hoàn toàn trở lại cuộc sống bình thường cho tới ngày rút thanh. Thời gian lưu thanh là 3 năm. Trở ngại của phẫu thuật là phải rạch thêm da ở phần lồi ngực để cắt gọt xương, sụn và để lại sẹo sau đó. Tuy nhiên đường rạch thường rất nhỏ, có thể di động da, chuyển dịch đường mổ để có thể cắt xương ở những vị trí xa đường mổ. Sẹo sau mổ thường mờ nhanh, nhiều khi khó nhận thấy. Những người có cơ địa sẹo lồi có thể bị ảnh hưởng tuy nhiên chúng tôi chưa gặp trường hợp nào.

Việc đẩy phần lõm ở phía trong ra là rất quan trọng, nếu không đẩy đủ phần lõm ra thì không thể tạo lồng ngực tròn đều sau phẫu thuật được và phần lồi cũng khó cắt gọt hết được

Lồi ngực dọc khó phẫu thuật sửa chữa do rất khó đẩy toàn bộ phần xẹp 2 bên ngực và cũng không thể cắt gọt hết phần lồi vì nó thường là gần toàn bộ thân xương ức. Hiện nay chúng tôi chưa có chỉ định phẫu thuật chỉnh sửa cho loại hình lồi ngực này

\section{KẾT LUẬN}

Phẫu thuật lồi ngực chủ yếu là giải quyết vấn đề thẩm mỹ, cho kết quả tốt với loại hình lồi ngực ngang. Phối hợp đẩy từ trong ra và cắt gọt những phần lồi ở ngoài có tác dụng "nắn" khung ngực tròn lại.

\section{TÀI LIỆU THAM KHẢO}

1. J Pediatr Surg. 2008 Aug;43(8):1468-73. doi: 10.1016/j.jpedsurg.2007.11.019.

\section{Reactive pectus carinatum in patients} treated for pectus excavatum.

Swanson JW1, Colombani PM.

2. Roviscek F, Sanger PW, Taylor FH. The surgical treatment of chondrosternal prominence (pectus carinatum). J Thorac Cardiovasc Surg. 1963;45:691-701.

3. Welsh KJ, Vos A. Surgical correction of pectus carinatum (pigeon breast). J Pediatr Surg. 1973;8:659-67. 